\title{
Long-term disease control of metastatic type 2 papillary renal cell carcinoma using local treatment and molecular targeted therapy: A case report
}

\author{
YUICHI ARAI ${ }^{1}$, YOSUKE KITAMURA ${ }^{1}$, KOSUKE MIYAI ${ }^{2}$, MINA HATANAKA ${ }^{1}$, \\ HIROFUMI HASHIMOTO ${ }^{3}$, AKIO HORIGUCHI ${ }^{1}$ and KEIICHI ITO ${ }^{1}$ \\ ${ }^{1}$ Department of Urology; ${ }^{2}$ Department of Laboratory Medicine and ${ }^{3}$ Department of Surgery, \\ National Defense Medical College, Tokorozawa, Saitama 359-8513, Japan
}

Received May 22, 2020; Accepted January 29, 2021

DOI: $10.3892 / \mathrm{mco} .2021 .2233$

\begin{abstract}
A 46-year-old man underwent right partial nephrectomy for type 2 papillary renal cell carcinoma (PRCC) in 2011. Lung metastasis and lymph node (LN) metastases around the inferior vena cave appeared in 2012. A right radical nephrectomy and extensive LN dissection was performed and the resection of lung metastasis was performed one month after the nephrectomy. Mediastinal LN metastases occurred in 2013, and resection of the affected LNs was performed. Sunitinib and zoledronic acid was started in 2014 because mediastinal LN swelling and multiple bone metastases appeared. Sunitinib treatment was stopped soon after due to adverse events and axitinib treatment was started. Axitinib was effective and the patient had stable disease for 30 months. Adverse events were successfully controlled by dose reduction and periodic drug withdrawal schedules (for example, 5 days on, 2 days off). Axitinib was further continued for 19 months as the metastatic lesions had progressed slowly. Temsirolimus treatment was started in 2019, but it was stopped after three cycles due to interstitial pneumonia. The patient died 80 months after the initial recurrence. Using multidisciplinary treatment, durable disease control was achieved in a patient with metastatic type 2 PRCC.
\end{abstract}

\section{Introductions}

Recently, the prognosis of patients with metastatic renal cell carcinoma (RCC) has been improved by molecular targeted therapies (1) and immune checkpoint inhibitors (2). However,

Correspondence to: Dr Keiichi Ito, Department of Urology, National Defense Medical College, 3-2 Namiki, Tokorozawa, Saitama 359-8513, Japan

E-mail: itok@ndmc.ac.jp

Key words: type 2 papillary renal cell carcinoma, axitinib, metastasectomy, periodic drug withdrawal schedule optimal treatment strategies for metastatic non-clear cell RCC (nccRCC) has yet to be established. In previous studies, molecular targeted therapies, especially sunitinib, have shown clinical efficacy for the treatment of metastatic nccRCC (3-7). The NCCN guidelines (2020 version) indicate that clinical trial or sunitinib is recommended at present for metastatic nccRCC. In nccRCC papillary renal cell carcinoma (PRCC) is the leading histology (8). PRCC is divided into type 1 and type 2, with type 2 PRCC showing worse prognosis compared with type 1 (9). In phase 2 clinical trial evaluating the efficacy of sunitinib for metastatic PRCC, overall survival (OS) of type1 PRCC was 17.8 months, and that of type 2 was 12.4 months (10).

In this report, we present a patient with metastatic type 2 PRCC whose metastatic lesions were controlled for a long time by multidisciplinary treatments including metastasectomies, axitinib, zoledronic acid (ZA), and radiation therapy.

\section{Case report}

A 46-year-old man with hematospermia was presented to a urologic clinic in April, 2011. A right renal tumor was found by ultrasound, and the patient was referred to our hospital. The tumor (35 $\mathrm{mm}$ in maximal diameter) was located in the middle of the right kidney, and RCC or fat-poor angiomyolipoma was suspected by contrast-enhanced computed tomography (CT) (Fig. 1A and B). A right partial nephrectomy was performed in July, 2011. Pathological diagnosis was type2 PRCC (Fig. 1C and D). A lung metastasis (S6) and paracaval lymph node (LN) metastases appeared in March, 2012 (Fig. 2A and B). After five cycles of temsirolimus, right radical nephrectomy and extensive LN dissection around the inferior vena cava (IVC) and right common iliac vein were performed in June, 2012, and the resection of the lung metastasis was performed one month after the nephrectomy. Then, radiological complete remission was achieved. LN swellings at the right tracheal bifurcation was found by CT in August, 2013 (Fig. 2C). After three cycles of temsirolimus, mediastinal LN dissection was performed in October, 2013. Mediastinal LNs (Fig. 2D) were swollen again, and multiple bone metastases [sternum, right fifth rib, thoracic spine (5-7th 
vertebrae), left ilium, and right pubis] appeared in 2014. The clinical course of the patient, including local treatments, medical treatments, and treatment-related adverse events are shown in Fig. 3. Sunitinib (37.5 mg/day) and ZA (4 mg/month) were started in June, 2014. Sunitinib was stopped within two weeks because of adverse events (AEs) including fever, malaise, and liver dysfunction. After the patient had recovered from the AEs, axitinib (10 mg/day) was started as a second-line treatment in July, 2014. ZA was continued after the axitinib administration. Because of diarrhea and hoarseness, the treatment schedule of axitinib was changed to a periodic drug withdrawal schedule (5 days-on, 2 days-off) in October, 2014. Next, the daily dose of axitinib was reduced to $8 \mathrm{mg}$ (5 days-on, 2 days-off) to control severe diarrhea in December, 2014. Stereotactic radiation therapy (total 30 Gray, 10 fractions) was performed for bone metastasis at the left ilium in November, 2015 because only the iliac metastasis appeared to be an active lesion among all bone metastases in the bone scintigraphy. The periodic drug withdrawal schedule of axitinib $(8 \mathrm{mg} /$ day, 5 days-on, 2 days-off) was changed to the next schedule $(8 \mathrm{mg} / \mathrm{day}$, 4 days-on, 3 days-off) due to renal dysfunction and proteinuria in April, 2017. Mediastinal LN metastases and bone metastases was stable for 30 months after the axitinib administration (Fig. 4). Disease progression was confirmed in June, 2017 due to the appearance of multiple small lung metastases. Because the metastatic lesions progressed slowly after the disease progression, axitinib was continued for another 19 months in accordance with the patient's request. The schedule of axitinib was then changed to a third schedule ( $8 \mathrm{mg} /$ day, 3 days-on, 3 days-off) due to symptoms of anorexia, dyspnea, and muscle pain in April, 2018. Patient was hospitalized due to severe back pain in September, 2018, and palliative radiotherapy was performed for a compression fracture due to metastasis (L1 lumber vertebrae). Axitinib was stopped in October, 2019. Temsirolimus was then administered, but interstitial pneumonia occurred after three cycles of temsirolimus. Although steroid pulse therapy was performed, respiratory and general condition became worse. The patient died in November, 2019. By multidisciplinary treatments including metastasectomy, axitinib, ZA, and radiation therapy, the patient survived for 80 months after the initial recurrence.

\section{Discussion}

This patient with metastatic type 2 PRCC could survive 80 months after the initial recurrence by multidisciplinary treatments including metastasectomies, axitinib, ZA, and radiation therapy. Patients with metastatic type 2 PRCC generally have poor prognosis. In a clinical trial evaluating the efficacy of sunitinib for metastatic PRCC, the median OS in type 2 PRCC was 12.4 months (10). Metastasectomies and axitinib appeared to be especially effective in the present case.

The NCCN guidelines (2020 version) indicate that clinical trial or sunitinib is the recommended treatment for metastatic nccRCC, and cabozantinib and everolimus are options. At the beginning of targeted era, mammalian target of rapamycin (mTOR) inhibitor, temsirolimus, was report- edly effective compared with interferon- $\alpha$ for metastatic nccRCC (11). A comparative study between temsirolimus and tyrosine kinase inhibitors (TKIs) in metastatic nccRCC does not exist at present. The superiority of sunitinib compared with everolimus in nccRCC treatment has been reported in two clinical trials $(12,13)$. The ASPEN trial reported that the progression-free survival (PFS) of sunitinib was longer than that of everolimus (12). The ESPN trial reported that both PFS and OS of sunitinib were longer than those of everolimus (13). Among other TKIs, the overall response rate of pazopanib was reportedly $39 \%$ in the treatment of metastatic nccRCC (6). There are few studies evaluating the clinical efficacy of systemic therapies in metastatic PRCC. In clinical trial evaluating the efficacy of sunitinib for metastatic PRCC, the median PFS and OS were 6.6 and 17.8 months in type 1 PRCC, and 5.5 and 12.4 months in type 2, respectively (10). In a Japanese multicenter study evaluating metastatic PRCC in which most PRCC cases (91.4\%) were type 2, the prognosis in the era of targeted therapy (OS=22.5 months) was improved compared with that in the cytokine era (OS=6.3 months). PRCC patients treated with TKIs in both first-line and second-line treatments ( $\mathrm{OS}=31.4$ months) showed better prognosis than those with mTOR inhibitors in first-line or second-line (OS=12.9 months) (14).

In our case, the second-line use of axitinib was effective and achieved a durable stable disease (SD). There have been few reports in which axitinib showed efficacies for metastatic PRCC $(15,16)$. In our case, AEs were relieved by dose reduction and the setting of periodic drug withdrawal schedules of axitinib, and axitinib could be continued for a long time. The half-life period of axitinib was reportedly short (4.8-5.9 h) (17). Axitinib has a characteristic that AEs can be relieved in a short period because of its short half-life period. Then, axitinib can be started again after the short drug withdrawal period. The risk of regrowth should be low due to the short drug withdrawal. In our previous report of a clear cell RCC patient with metastasis at the paranasal sinus, AEs could be relieved effectively by using periodic drug withdrawal schedules of axitinib and axitinib could be used for more than 30 months (18). Takayama et al also reported a similar RCC case in which intermittent use of axitinib was effective (19).

There is a possibility that prognosis of this patient was improved by metastasectomies. LN metastases around the right common iliac vein and IVC at the time of LN dissection were pathologically confirmed. However, the relapse did not occur in the abdominal and pelvic areas after the extensive LN dissection. This appeared to indicate that LN metastases in the abdominal and the pelvic areas were completely resected by the initial LN dissection. Moreover, the three metastasectomies including the initial LN dissection around the IVC and right iliac vein, the resection of lung metastasis, and the mediastinal LN dissection could delay the timing of TKI administration for two years. Those metastasectomies might contribute to improve the patient's prognosis. In the cytokine era, an efficacy of LN dissection on radical nephrectomy was suggested in PRCC (20). Metastatectomy should be performed appropriately for patients with metastatic PRCC similar to clear cell RCC when radiological complete remission can be achieved by metastasectomy. 
A

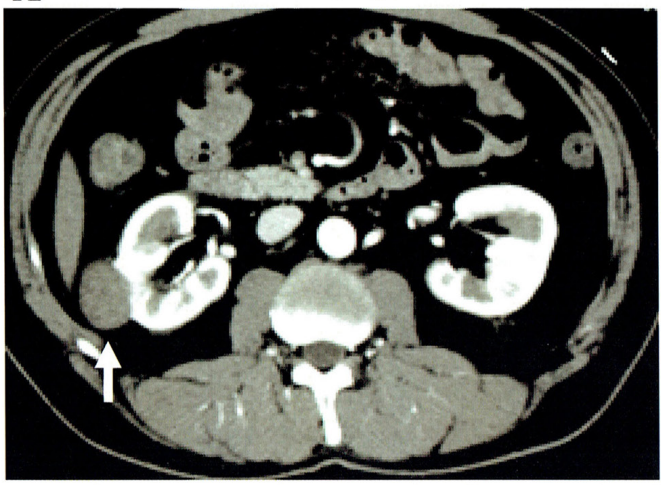

C

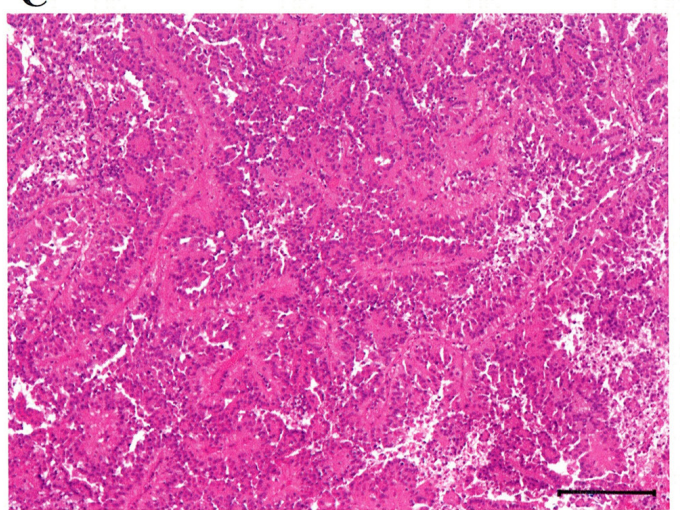

B

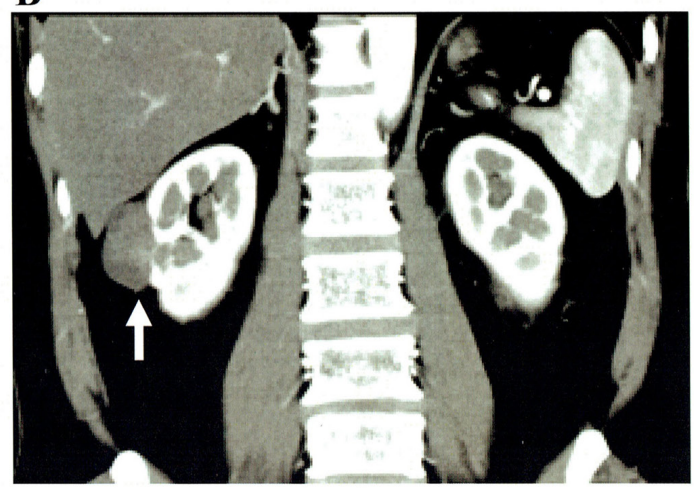

D

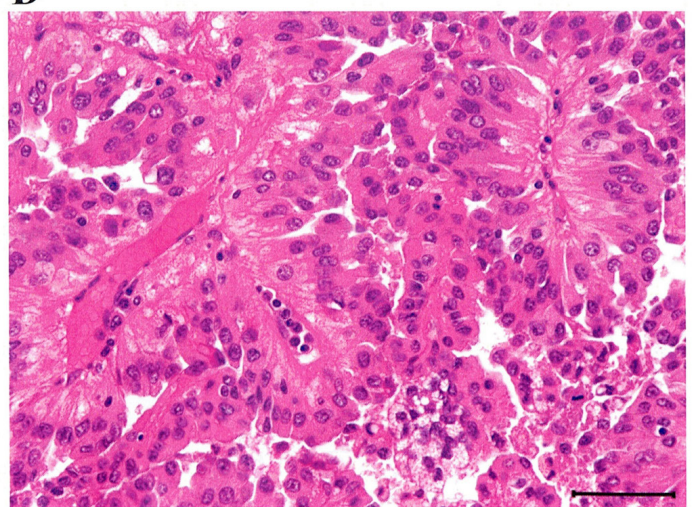

Figure 1. Radiological and pathological findings of the primary tumor. (A and B) Contrast-enhanced computed tomography images. A tumor (35 mm in maximal diameter) was located in the middle of the right kidney, and RCC or fat-poor angiomyolipoma was suspected. (C and D) Microscopically, the tumor had papillary architecture. The tumor cells contained abundant eosinophilic cytoplasm with high nuclear grade (Fuhrman nuclear grade 3 ). The tumor was diagnosed as type 2 papillary RCC. (C) magnification, x100; scale bar, $200 \mu \mathrm{m}$. (D) magnification, x400; scale bar, $50 \mu \mathrm{m}$. RCC, renal cell carcinoma.

A

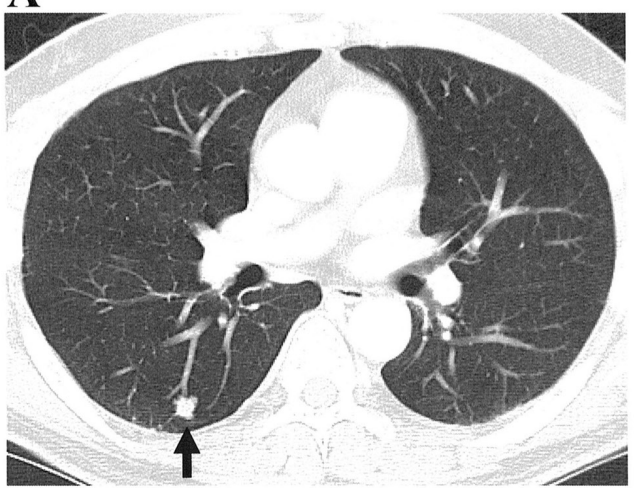

C

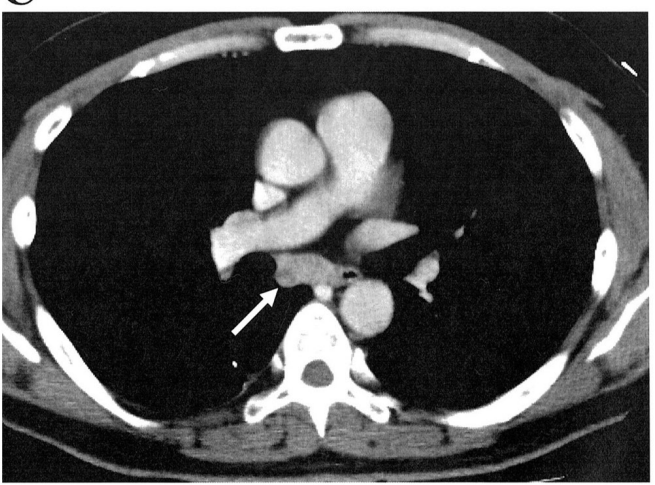

B

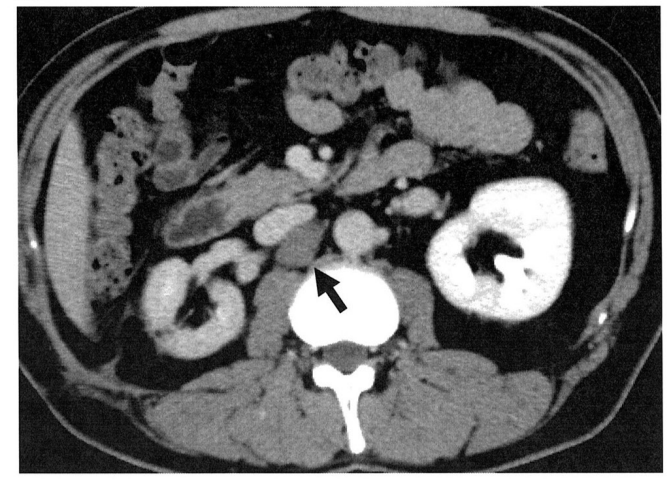

D

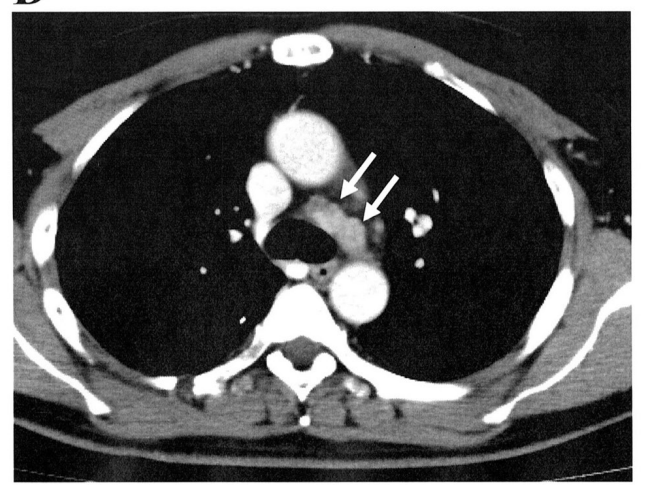

Figure 2. CE-CT images. (A and B) CE-CT images of a (A) lung metastasis (S6) (black arrow) and (B) paracaval lymph node metastases (black arrow) that appeared in 2012. (C) CE-CT of lymph node swellings at the right tracheal bifurcation (white arrow) found in 2013. (D) CE-CT of mediastinal lymph nodes (white arrows) that were swollen again in 2014. CE-CT, Contrast-enhanced computed tomography. 


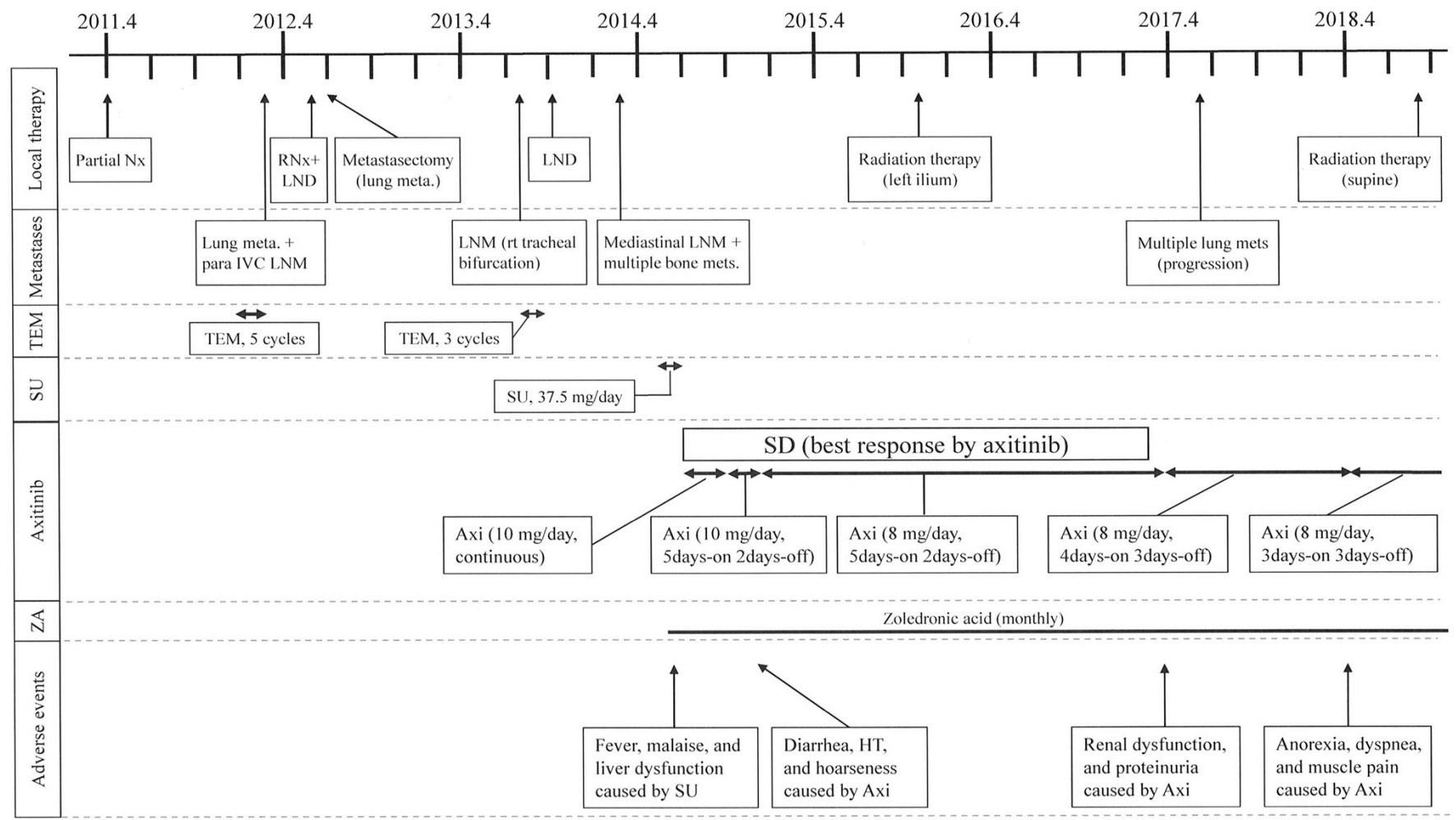

Figure 3. The time course of treatments for the patient with metastatic type 2 papillary renal cell carcinoma. Axi, axitinib; HT, hypertension; IVC, inferior vena cava; LND, lymph node dissection; LNM, lymph node metastasis; RNx, radical nephrectomy; SD, stable disease; SU, sunitinib; TEM, temsirolimus; ZA, zoledronic acid.

A

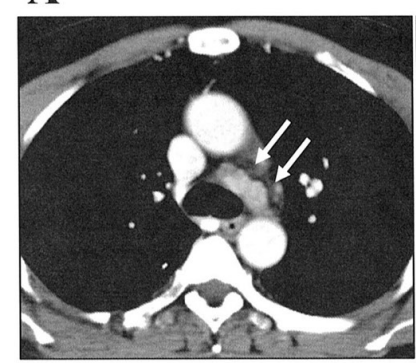

$\mathbf{E}$

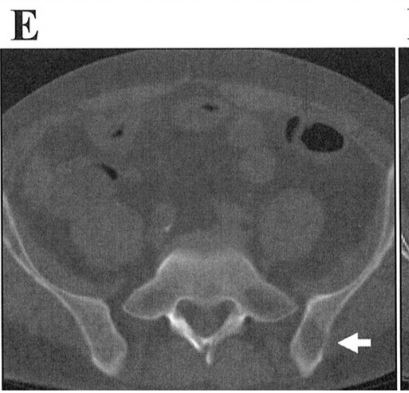

B

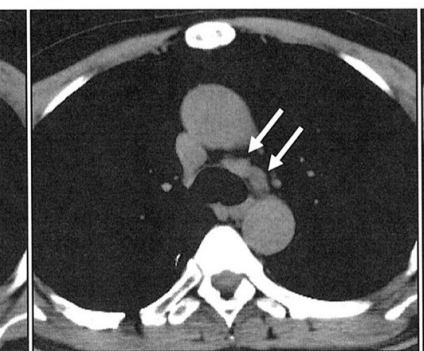

F
C

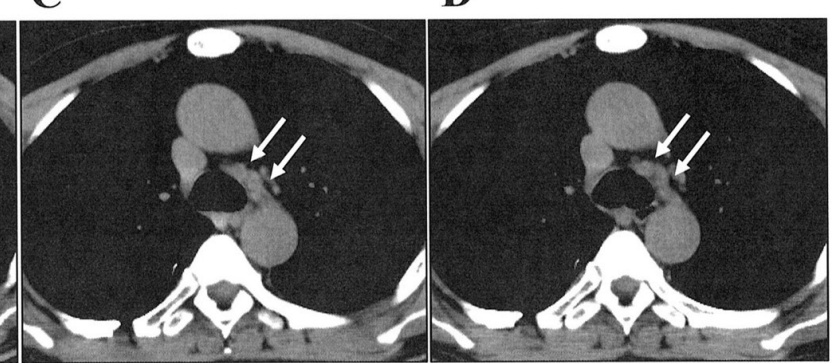

G
D

H 
schedules could reduce AEs and enable to continue axitinib usage.

\section{Acknowledgements}

Not applicable.

\section{Funding}

No funding was received.

\section{Availability of data and materials}

Data sharing is not applicable to this article, as no datasets were generated or analyzed during the present study.

\section{Authors' contributions}

YA contributed to the study concept, design, data collection and writing of the manuscript. YK contributed to data collection and the revision of the manuscript. MH contributed to data collection and the revision of the manuscript. HH contributed to data collection and the revision of the manuscript. KM contributed to data collection, pathological diagnosis and the revision of the manuscript. AH contributed to the study concept, design and the revision of the manuscript. KI contributed to the study concept, design, data collection, writing and the revision of the manuscript, and the supervision of the manuscript. The authenticity of all the raw data was assessed by YA, KM, AH and KI. All authors read and approved the final manuscript.

\section{Ethics approval and consent to participate}

Ethical approval was granted from the Ethics Committee of National Defense Medical College.

\section{Patient consent for publication}

Written informed consent for the publication of any associated data was obtained from the patient's wife.

\section{Competing interests}

The authors declare that they have no competing interests.

\section{References}

1. Wahlgren T,Harmenberg U, Sandström P,Lundstam S, Kowalski J, Jakobsson M, Sandin R and Ljungberg B: Treatment and overall survival in renal cell carcinoma: A Swedish population-based study (2000-2008). Br J Cancer 108: 1541-1549, 2013.

2. Motzer RJ, Tannir NM, McDermott DF, Arén Frontera O, Melichar B, Choueiri TK, Plimack ER, Barthélémy P, Porta C, George S, et al: Nivolumab plus ipilimumab versus sunitinib in advanced renal-cell carcinoma. N Engl J Med 378: 1277-1290, 2018.

3. Tannir NM, Plimack E, Ng C, Tamboli P, Bekele NB, Xiao L, Smith L, Lim Z, Pagliaro L, Araujo J, et al: A phase 2 trial of sunitinib in patients with advanced non-clear cell renal cell carcinoma. Eur Urol 62: 1013-1019, 2012.

4. Lee JL, Ahn JH, Lim HY, Park SH, Lee SH, Kim TM, Lee DH, Cho YM, Song C, Hong JH, et al: Multicenter phase II study of sunitinib in patients with non-clear cell renal cell carcinoma. Ann Oncol 23: 2108-2114, 2012.
5. Matrana MR, Baiomy A, Campbell M, Alamri S, Shetty A, Teegavarapu P, Kalra S, Xiao L, Atkinson B, Corn P, et al: Outcomes of patients with metastatic non-clear-cell renal cell carcinoma treated with pazopanib. Clin Genitourin Cancer 15: e205-e208, 2017.

6. Jung KS, Lee SJ, Park SH, Lee JL, Lee SH, Lim JY, Kang JH, Lee S, Rha SY, Lee KH, et al: Pazopanib for the treatment of non-clear cell renal cell carcinoma: A single-arm, open-label, multicenter, phase II study. Cancer Res Treat 50: 488-494, 2018.

7. Park I, Lee SH and Lee JL: A multicenter phase II trial of axitinib in patients with recurrent or metastatic non-clear-cell renal cell carcinoma who had failed prior treatment with temsirolimus. Clin Genitourin Cancer 16: e997-e1002, 2018.

8. Moch H, Humphrey PA, Ulbright TM and Reuter VE: WHO classification of tumours of the Urinary System and Male Genital Organs. Lyon: IARCPress, 2016.

9. Mejean A, Hopirtean V, Bazin JP, Larousserie F, Benoit $\mathrm{H}$, Chrétien Y, Thiounn N and Dufour B: Prognostic factors for the survival of patients with papillary renal cell carcinoma: Meaning of histological typing and multifocality. J Urol 170: 764-767, 2003.

10. Ravaud A, Oudard S, De Fromont M, Chevreau C, Gravis G, Zanetta S, Theodore C, Jimenez M, Sevin E, Laguerre B, et al: First-line treatment with sunitinib for type 1 and type 2 locally advanced or metastatic papillary renal cell carcinoma: A phase II study (SUPAP) by the French Genitourinary Group (GETUG) $†$. Ann Oncol 26: 1123-1128, 2015.

11. Dutcher JP, de Souza P, McDermott D, Figlin RA, Berkenblit A, Thiele A, Krygowski M, Strahs A, Feingold J and Hudes G: Effect of temsirolimus versus interferon- $\alpha$ on outcome of patients with advanced renal cell carcinoma of different tumor histologies. Med Oncol 26: 202-209, 2009.

12. Armstrong AJ, Halabi S, Eisen T, Broderick S, Stadler WM, Jones RJ, Garcia JA, Vaishampayan UN, Picus J, Hawkins RE, et al: Everolimus versus sunitinib for patients with metastatic non-clear cell renal cell carcinoma (ASPEN): A multicentre, open-label, randomised phase 2 trial. Lancet Oncol 17: 378-388, 2016.

13. Tannir NM, Jonasch E, Albiges L, Altinmakas E, Ng CS, Matin SF, Wang X, Qiao W, Dubauskas Lim Z, Tamboli P, et al: Everolimus versus sunitinib prospective evaluation in metastatic non-clear cell renal cell carcinoma (ESPN): A randomized multicenter phase 2 trial. Eur Urol 69: 866-874, 2016.

14. Ito K, Mikami S, Tatsugami K, Masumori N, Shinohara N, Kondo T, Nakanishi S, Nagashima Y, Eto M, Kamba T, et al: Clinical outcomes in patients with metastatic papillary renal-cell carcinoma: A multi-institutional study in Japan. Clin Genitourin Cancer 16: e1201-e1214, 2018.

15. Mori J, Nakayama Y, Hiragino T and Matsuyama H: Successful treatment of peritoneal dissemination recurrence with axitinib in papillary renal cell carcinoma: A case report. Hinyokika Kiyo 64: 45-48, 2018 (In Japanese).

16. Ishii G, Hatano T, Endo K, Seki K, Yamada H, Kimura T and Egawa S: A case of papillary renal cell carcinoma type 2 resistant to sunitinib responded to second line therapy with axitinib. Nihon Hinyokika Gakkai Zasshi 105: 129-133, 2014 (In Japanese).

17. Mukohara $T$, Nakajima $H$, Mukai $H$, Nagai S, Itoh $K$, Umeyama Y, Hashimot J and Minami H: Effect of axitinib (AG-013736) on fatigue, thyroid-stimulating hormone, and biomarkers: A phase I study in Japanese patients. Cancer Sci 101: 963-968, 2010.

18. Arai Y, Ito K, Tachi K, Koga A, Shinchi Y, Masunaga A, Isono M and Asano T: Metastatic renal cell carcinoma in paranasal sinus for which periodic drug withdrawal schedule of axitinib was effective: A case report. Hinyokika Kiyo 62: 465-471, 2016 (In Japanese).

19. Takayama T, Nagata M,Kai F, Sugiyama T and Ozono S: Axitinib controlled metastatic renal cell carcinoma for 5 years. Jpn J Clin Oncol 43: 747-751, 2013

20. Margulis V, Tamboli P, Matin SF, Swanson DA and Wood CG: Analysis of clinicopathologic predictors of oncologic outcome provides insight into the natural history of surgically managed papillary renal cell carcinoma. Cancer 112: 1480-1488, 2008.

This work is licensed under a Creative Commons Attribution-NonCommercial-NoDerivatives 4.0 International (CC BY-NC-ND 4.0) License. 